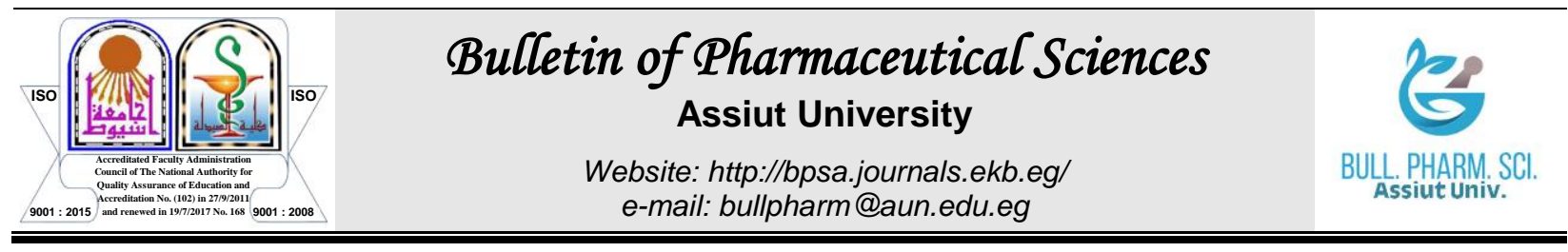

\title{
THE SIMVASTATIN EFFECT ON ACETYL COA CARBOXYLASE1 AND FATTY ACID SYNTHASE GENE EXPRESSION IN RAT FED WITH HIGH FAT DIETS AND ITS ASSOCIATION WITH FATTY ACID PROPORTION AND CONCENTRATION
}

\author{
Hamid Sepehri ${ }^{1}$, Abbas Nezhadebrahimi ${ }^{2}$, Majid Marjani ${ }^{3}$ and Abdoljalal Marjani ${ }^{4 *}$ \\ ${ }^{1}$ Neuroscience Research Center, Department of Physiology, Faculty of Medicine, Golestan \\ University of Medical Sciences, Gorgan, Iran \\ ${ }^{2}$ Student Research Committee, Metabolic Disorders Research Center, Department of \\ Biochemistry and Biophysics, Gorgan Faculty of Medicine, Golestan University Medical \\ Sciences, Gorgan, Iran \\ ${ }^{3}$ Faculty of Pharmacy, Eastern Mediterranean University, Famagusta, North Cyprus, Mersin \\ 10, Turkey \\ ${ }^{4}$ Metabolic Disorders Research Center, Department of Biochemistry and Biophysics, Gorgan \\ Faculty of Medicine, Golestan University Medical Sciences, Gorgan, Iran
}

\begin{abstract}
The aim of study was to determine the effect of different dosages of simvastatin on gene expression of Acetyl CoA Carboxylase 1 (ACC1) and Fatty Acid Synthase (FAS) in Wister rat hepatic tissues fed with high fat diets (HFD) and its association with serum fatty acid proportion and concentration. Four groups of rats (G1 to G4) were included. ACC1 and FAS expressions were analyzed by Real time quantitative polymerase chain reaction. Fatty acid concentration was measured by gas chromatography. There were significant differences when $G 4$ versus $G 3, G 4$ and $G 3$ versus $G 1$ and $G 4$ and $G 3$ versus $G 2$ was compared for total fatty acid concentration. The proportion of oleic acid to stearic acid showed significant decrease when G4 versus G3, G4 versus G2 and G4 versus G1 groups were compared, but the proportion of stearic acid to palmitic acid, linoleic acid to oleic acid (G3 versus G4) and oleic acid to palmitic acid in G4 increased when compared to G1, G2 and G3 groups. Treatment with simvastatin significantly increases or decreases some fatty acid ratio, serum fatty acid and total fatty acid concentrations. We also found that HFD led to no significant differences in ACC1 and FAS mRNA expression. Simvastatin increases proportion of linoleic acid to oleic acid, oleic acid to palmitic acid and oleic acid to stearic acid. Thus, statin therapy may be considered in prevention of cardiovascular and myocardial risk.
\end{abstract}

\section{INTRODUCTION}

Statins belong to hypocholesterolemic drug with a hexahydro-naphthalene ring and hydroxy-lactone in their structure. Statins can be divided into two groups. Group 1 statins include simvastatin, lovastatin, compactin, and pravastatin and Group 2 statins consist of rosuvastatin, atorvastatin, fluvastatin, andcerivastatin. Group 2 statins show structural differences with the group 1 statins $^{1 \& 2}$.
Acetyl-CoA carboxylases (ACCs) are enzymes taking part in the synthesis of fatty acids. In humans, the ACC enzyme have two isoforms including ACC1 (ACC alpha) and ACC2 (ACC beta) isoforms which catalyze the changing of acetyl-CoA to malonyl-CoA ${ }^{3}$. ACC1 is a cytoplasmic enzyme and is expressed in liver and adipose tissues ${ }^{4}$. ACC2 is a mitochondrial membrane enzyme and is found in muscle and heart tissues ${ }^{5}$. A study has shown that the inhibition of ACCs may reduce fatty acid synthesis and increase fatty acid

Received in 5/6/2021 \& Accepted in 11/8/2021 
oxidation. High-diet feeding stimulates ACC1 expression in the liver leading to increased level of serum triglyceride ${ }^{6}$. In mammals, ACC is regulated by different mechanisms containing tissue-specific promoters, reversible phosphorylation and many metabolites ${ }^{3 \& 7}$. Studies on Escherichia coli have shown that there is a correlation between transcription of ACC genes and the rate of cellular growth, overexpression of ACC and increasing the level of fatty acid biosynthesis ${ }^{8}$, while studies on yeast (Saccharomyces cerevisiae) have indicated that expression of the ACC gene is correlated with phospholipid metabolism ${ }^{9}$.

Fatty acids are released from adipocyte tissues after lipolysis of triglyceride and from phospholipids after hydrolysis by phospholipases ${ }^{10}$. Fatty acids have an important role in the formation of triglycerides and production of low density lipoprotein (VLDL) in the liver. These may cause atherogenic dyslipidemia $^{11 \& 12}$.

Different findings have shown that statin therapy cannot change the fatty acid metabolism ${ }^{13-15}$. In Contrast, studies on animal models ${ }^{16}$ cultured cells ${ }^{17}$, and in mice after treatment with statin ${ }^{18}$ have been indicated that there is a moderate increase in fatty acid synthesis. It is reported that statins may affect fatty acid metabolism in liver ${ }^{18}$. Many studies have been done to evaluate the effects of statins on the metabolism of fatty acid in humans, but the findings are inconsistent ${ }^{19}$. Findings suggested that statins are associated with a decrease in the fatty acid levels. The reduction in the fatty acid levels was independent to type of statins, duration of treatment and drug dosage $^{20}$.

FAS is expressed at widely varying levels in nearly all human and mouse tissues. Some studies have been described that nutrients and hormones affect FAS expression ${ }^{21}$. Variations in FAS expression and enzyme activity have been involved in some diseases in humans ${ }^{22 \& 23}$. It has been reported that FAS can be used as a biomarker of metabolic stress in humans ${ }^{24}$.

A Study has shown that the effects of simvastatin in subjects with high or low fatty acids, dietary treatment were different ${ }^{25}$. Some studies in animals and cultured cell lines indicated that simvastatin has an important role in increasing the level of long-chain polyunsaturated fatty acid formation ${ }^{26 \& 27}$.
Study of Julaet al. has revealed that dietary treatment did not make change total fatty acid level, but there was a reduction in the proportion of palmitic acid and stearic acid from total fatty acids ${ }^{28}$. They have also shown that $\alpha$-linolenic, eicosatetraenoic and docosahexaenoic acid levels were reduced by simvastatin treatment ${ }^{28}$. The effects of dietary treatment and simvastatin on the fatty acid level are not known certainty in humans. There is a limited study on statins effects on metabolism of fatty acid in humans ${ }^{29}$. Therefore, the aim of this study was to determine the effect of different dosages of simvastatin on gene expression of Acetyl CoA Carboxylase 1 (ACC1) and Fatty Acid Synthase (FAS) in rat hepatic tissues fed with high fat diets (HFD) and its association with some serum fatty acid proportion and concentration.

\section{MATERIALS AND METHODS}

Eight Wister rats were placed per cage in a standard condition in an atmosphere of $50 \pm$ $10 \%$, relative humidity at $23 \pm 10^{\circ} \mathrm{C}$ and with a 12 hrs. light / a 12 hrs. dark. Rats (Total numbers of rats were 32) were able to drink water and to eat food freely. After adaption of rats to the environment of laboratory (after 1 week), rats were separated into 4 different groups (Table 1). The rats were provided from Institute of Pasteur, Tehran, Iran.

The Ethical Committee of Research Deputy of Golestan University of Medical Sciences approved the study (IR.GOUMS.REC.1396.41). The groups G2G4 were fed with a HFD according to Srinivasan et al protocol ${ }^{30}$. HFD ingredients were shown in table 2 .

At the end of study (After 10 weeks), chloroform was used to anesthetize rats in groups G1-G4 in the Metabolic Disorders Research Center (School of Medicine). After $12 \mathrm{hrs}$. fasting, blood samples were collected in clean tubes. Serum was separated from collected blood after $10 \mathrm{~min}$ at 4,000 r/min centrifugation. The serum samples were stored at $-20^{\circ} \mathrm{C}$ until use for determination of fatty acid composition in groups G1-G4. At the end of study, the rats were sacrificed by chemical method and they buried in special place of animal house of Golestan University of Medical Sciences. 
Table 1: study groups of rats and its condition

\begin{tabular}{|l|l|}
\hline \multicolumn{1}{|c|}{ Groups } & \multicolumn{1}{|c|}{ Condition } \\
\hline $\begin{array}{l}\text { Group1 (G1 or } \\
\text { Control), } \mathbf{n = 8}\end{array}$ & $\begin{array}{l}\text { Standard laboratory diet (30-60 kcal/gr, 13\% calories from fat, 25\% } \\
\text { calories from protein, and 62\% calories from carbohydrate) without } \\
\text { simvastatin for 10 weeks. }\end{array}$ \\
\hline Group 2 (G2), n=8 & High Fat Diet (HFD) and without simvastatin for 10 weeks. \\
\hline Group 3 (G3), n = 8 & $\begin{array}{l}\text { High Fat Diet (HFD) and simvastatin 2 mg/kg of body weight/day for } \\
10 \text { weeks. }\end{array}$ \\
\hline Group 4 (G4), n = 8 & $\begin{array}{l}\text { High Fat Diet (HFD) and simvastatin 20 mg/kg of body weight/day for } \\
10 \text { weeks. }\end{array}$ \\
\hline
\end{tabular}

Table 2: HFD ingredients supplied for the groups G2-G4

\begin{tabular}{|l|l|}
\hline $\begin{array}{l}\text { Powdered normal pelleted } \\
\text { diet(NPD) }\end{array}$ & $365 \mathrm{gr} / \mathrm{Kg}$ \\
\hline Sheep fat & $310 \mathrm{gr} / \mathrm{Kg}$ \\
\hline Casein & $250 \mathrm{gr} / \mathrm{Kg}$ \\
\hline Cholesterol & $10 \mathrm{gr} / \mathrm{Kg}$ \\
\hline Vitamin and mineral mix & $60 \mathrm{gr} / \mathrm{Kg}$ \\
\hline Methionine & $3 \mathrm{gr} / \mathrm{Kg}$ \\
\hline Yeast powder & $1 \mathrm{gr} / \mathrm{Kg}$ \\
\hline Sodium chloride & $1 \mathrm{gr} / \mathrm{Kg}$ \\
\hline
\end{tabular}

Extraction of RNA was carried out from the hepatic tissue. RNA from hepatic tissue was isolated by using RNx plus commercial Kit (Iran). Real time quantitative polymerase chain reaction (RT-PCR) method (7300 RT-PCR system, Applied Biosystems, Foster, CA, USA) was used after reverse transcription to cDNA, to analyze the abundances of Acetyl CoA Carboxylase 1 (ACC1), Fatty Acid Synthase (FAS) and Beta-actin (ACTB) as described before by Pocathikorn et $\mathrm{al}^{31}$. In this study, the used conditions were shown below:

$1 \mu \mathrm{g}$ of RNA was treated with DNaseI Rnasefree (IRAN) for $30 \mathrm{~min}$, in $37^{\circ} \mathrm{C}$ to deplete possible DNA contamination. $2 \mu 1$ RNA sample was used for reverse transcription reaction by cDNA Synthesis Kit (Iran). Complementary DNA was used as a target for amplification of the target genes using specific primer sequences. The used primer sequences are shown in table 3. Expression of genes were shown as the relative levels of mRNA after normalization with housekeeping gene $(A C T B)$ using the $-2 \Delta^{\mathrm{ct}}$ formula.
The RNA integrity was checked by agarose gel electrophoresis and safe stain staining ( $\mathrm{Gel}$ is not shown here). Reverse transcription of total RNA (One micro liter) was done by reverse Aid First Strand cDNA synthesis commercial kit (Iran).

Chloroform-methanol (2:1) was used to extract lipids from the serum to determine serum total fatty acid composition. $14 \%$ boron trifluoride in methanol was used to synthesize the fatty acid methyl esters. A gas chromatography was used to analyze the methyl esters (Varian CP-3800; Varian Inc, Walnut Creek, Calif). The apparatus was provided with a 30-m_0.25-mm glass capillary column (stationary phase 50\% cyanopropylphenyl-methoxypolysiloxane; J \& W Scientific, Folsom, Calif) ${ }^{32}$. During the analysis run, the temperature of oven elevated $5^{\circ} \mathrm{C} / \mathrm{min}$ from $140^{\circ} \mathrm{C}$ to $220^{\circ} \mathrm{C}$. Different standards were used to show the peaks on the basis of retention times. As an internal standard, we used heptadecanoic acid (C17:0). A gas chromatography was used to quantify the fatty acids by peak areas relative to heptadecanoic acid.

\section{Statistical analysis}

The data was analyzed by SPSS -16 versions (SPSS, Chicago, IL, USA). The data were indicated as the mean \pm SD. Normal distribution of data was analyzed by Kolmogorov-Smirnov test. Comparison of groups after the 10-week period for normally and non-normally of data was carried out by Mann-Whitney U-test. Comparison of intergroup was done by One-way ANOVA followed by Turkey's post hoc test. The $P$ value $<0.05$ was considered significant. 
Table 3 : Forward and reverse primer sequences of the ACC1, FAS and $\beta$-actin genes

\begin{tabular}{||l|l|l||}
\hline Gene names & Forward primer $\left(\mathbf{5}^{\prime} \ldots \mathbf{3}^{\prime}\right)$ & Reverse primer $\left(\mathbf{5}^{\prime} \ldots . . \mathbf{3}^{\prime}\right)$ \\
\hline ACC1 & TGAAGGGCTACCTCTAATG & TCACAACCCAAGAACCAC \\
\hline ACAS & ATTGCATCAAGCAAGTGCAG & GAGCCGTCAAACAGGAAGAG \\
\hline
\end{tabular}

The RT-PCR experiments were done with the following condition as it showed in table 4.

Table 4: The RT-PCR conditions for study groups G1-G4

\begin{tabular}{||l|l||}
\hline $\begin{array}{l}\text { Initial } \\
\text { denaturation }\end{array}$ & $1 \mathrm{~min}$ in $95^{\circ} \mathrm{C}$ \\
\hline Denaturation & $\begin{array}{l}38 \text { cycles of } 20 \text { sec. in } \\
95^{\circ} \mathrm{C}\end{array}$ \\
\hline Annealing & $20 \mathrm{sec}$ in $60^{\circ} \mathrm{C}$ \\
\hline Extension & $40 \mathrm{sec}$ in $72^{\circ} \mathrm{C}$ \\
\hline
\end{tabular}

\section{RESULTS AND DISCUSSION}

\section{Results}

The mean effect of simvastatin on the expression of ACC1 and FAS are shown in Table 5. Expression of ACC1 decreased after 10 weeks' treatment with simvastatin when compared G1 versus G4 ( $p=0.614), \mathrm{G} 2$ versus G4 $(p=0.074)$ and G3 versus G4 $(p=0.204)$ while $\mathrm{G} 1$ versus $\mathrm{G} 2(p=0.344)$ and $\mathrm{G} 1$ versus G3 increased $(p=0.742)$. In group $4(\mathrm{G} 4)$, the decrease of ACC1 expression was notable, but there were no significant differences between all groups in $\mathrm{ACC} 1$ expressing.

Expression of FAS increased after 10 weeks' treatment with simvastatin when compared G1versus G2 ( $p=0.403)$, G1 versus G3 $(p=0.706), \mathrm{G} 1$ versus $\mathrm{G} 4(p=0.690), \mathrm{G} 2$ versus $\mathrm{G} 3(p=0.318)$ and $\mathrm{G} 2$ versus
G4 ( $p=0.260)$ but expression of FAS decreased when compared G3 versus G4 ( $p=$ 0.963), There was no significant difference between all groups in expression of FAS.

Table 6 shows serum fatty Acid composition in different study groups. High fat diet and different dosage of simvastatin treatment changed some serum total fatty acid concentration. Palmitic acid is significantly decreased while trans oleic acid, linoleic acid (G3 versus G4) and total fatty acid increased in G4 group when compared to other study groups $(P<0.05)$ (Table 6). The increase of total fatty acid was the highest in G4 group. There are significant differences when G4 versus G3, G4 and $\mathrm{G} 3$ versus $\mathrm{G} 1$ and $\mathrm{G} 4$ and $\mathrm{G} 3$ versus $\mathrm{G} 2$ was compared for total fatty acid concentration $(P<0.05)$. The proportion of oleic acid to stearic acid showed significant decrease when comparing G4 versus $\mathrm{G} 3$, G4 versus $\mathrm{G} 2$ and $\mathrm{G} 4$ versus G1 $(P<0.05)$ however the proportion of stearic acid to palmitic acid, linoleic acid to oleic acid (G3 versus G4) and oleic acid to palmitic acid in G4 group was increased when compared to G1, G2 and G3 study groups ( $P<$ 0.05) (Table 6).

Table 5: The effect of high fat diet and $\operatorname{simvastatin}(2$ and $20 \mathrm{mg} / \mathrm{kg} / \mathrm{mg} / \mathrm{day})$ on expression of ACC1 and FAS in liver tissue of rat

\begin{tabular}{|l|l|l||}
\hline Groups & ACC1 & FAS \\
\hline G1 $(\mathbf{n}=\mathbf{8})$ & $0.902 \pm 0.206$ & $0.056 \pm 0.15$ \\
\hline G2 $(\mathbf{n = 8 )}$ & $0.122 \pm 0.173$ & $0.070 \pm 0.009$ \\
\hline G3 $(\mathbf{n = 8 )}$ & $0.142 \pm 0.181$ & $0.111 \pm 0.25$ \\
\hline G4 $(\mathbf{n = 8 )}$ & $0.048 \pm 0.047$ & $0.090 \pm 0.205$ \\
\hline p-value & G1 versus G2 $(P=0.340)$ & G1 versus G2 $(P=0.403)$ \\
& G1 versus G3 $(P=0.742)$ & G1 versus G3 $(P=0.706)$ \\
& G1 versus G4 $(P=0.614)$ & G1 versus G4 $(P=0.690)$ \\
& G2 versus G3 $(P=0.094)$ & G2 versus G3 $(P=0.318)$ \\
& G2 versus G4 $(P=0.074)$ & G2 versus G4 $(P=0.260)$ \\
& G3 versus G4 $(P=0.204)$ & G3 versus G4 $(P=0.963)$ \\
\hline
\end{tabular}

G1G1: Control, G2: HFD, G3: HFD + Sim. 2mg/kg/day, G4: HFD + Sim. 20 mg/kg/day. HFD: High fat diet, Sim.: Simvastatin, ACC1: Acetyl CoA carboxylase 1 and FAS: Fatty acid synthase 
Table 6: Serum Fatty Acid composition of rats treated with high fat diets and different dosage of simvastatin

\begin{tabular}{|c|c|c|c|c|c|}
\hline Parameters & G1 & G2 & G3 & G4 & P-value \\
\hline $\begin{array}{l}\text { Palmitic acid (C16:0) } \\
(\mathrm{mg} / \mathrm{L})\end{array}$ & $48.89 \pm 2.01$ & $50.27 \pm 4.64$ & $48.31 \pm 5.63$ & $35.60 \pm 2.05$ & $\begin{array}{l}\text { G3 versus G4 } \\
(P<0.05)\end{array}$ \\
\hline $\begin{array}{l}\text { Palmitoleic acid } \\
(\text { C16:1 n-7) }(\mathrm{mg} / \mathrm{L})\end{array}$ & 0 & 0 & $26.15 \pm 0.34$ & $21 . .01 \pm 0.90$ & $P>0.05$ \\
\hline $\begin{array}{l}\text { Stearic acid (C18:0) } \\
(\mathrm{mg} / \mathrm{L})\end{array}$ & $16.09 \pm 4.92$ & $15.51 \pm 1.96$ & $13.85 \pm 1.83$ & $15.25 \pm 1.28$ & $\mathrm{P}>0.05$ \\
\hline $\begin{array}{l}\text { Trans oleic acid (C18: } \\
\text { 1n-9) (mg/L) }\end{array}$ & 0 & 0 & $0.66 \pm 0.18$ & $16.84 \pm 1.11$ & $\begin{array}{l}\text { G3 versus } \mathrm{G} 4 \\
(P<0.05)\end{array}$ \\
\hline $\begin{array}{l}\text { Oleic acid (C18: 1n- } \\
\text { 9) } \\
(\mathrm{mg} / \mathrm{L})\end{array}$ & $35.01 \pm 6.10$ & $34.18 \pm 5.36$ & $32.56 \pm 1.30$ & $29.45 \pm 9.63$ & $P>0.05$ \\
\hline $\begin{array}{l}\text { Linoleic acid (C18:2n- } \\
6) \\
(\mathrm{mg} / \mathrm{L})\end{array}$ & 0 & 0 & $42.85 \pm 1.34$ & $84.47 \pm 1.58$ & $\begin{array}{l}\text { G3 versus G4 } \\
(P<0.05)\end{array}$ \\
\hline $\begin{array}{l}\text { Total fatty acid } \\
(\mathrm{mg} / \mathrm{L})\end{array}$ & $100 \pm 1.46$ & $99.86 \pm 1.73$ & $\begin{array}{l}164.38 \pm \\
1.73\end{array}$ & $202.62 \pm 0.85$ & $\begin{array}{l}\mathrm{G} 4 \text { versus } \mathrm{G} 3 \\
(P<0.05) \\
\mathrm{G} 4 \text { and } \mathrm{G} 3 \\
\text { versus } \mathrm{G} 1(P< \\
0.05) \\
\mathrm{G} 4 \text { and } \mathrm{G} 3 \\
\text { versus } \mathrm{G} 2(P< \\
0.05)\end{array}$ \\
\hline $\begin{array}{l}\text { Stearic acid (C18:0) } \\
\text { to Palmitic acid } \\
(\mathrm{C16:0}) \text { ratio }\end{array}$ & $0.32 \pm 0.9$ & $0.31 \pm 0.04$ & $0.29 \pm 0.07$ & $0.45 \pm 0.16$ & $\begin{array}{l}\mathrm{G} 4 \text { versus } \mathrm{G} 3 \\
(P<0.05) \\
\mathrm{G} 4 \text { versus } \mathrm{G} 2 \\
(P<0.05) \\
\mathrm{G} 4 \text { versus } \mathrm{G} 1 \\
(P<0.05)\end{array}$ \\
\hline $\begin{array}{l}\text { Palmitoleic acid } \\
\text { (C16:1 n-7) to } \\
\text { Palmitic acid (C16:0) } \\
\text { ratio }\end{array}$ & 0 & 0 & $0.05 \pm 0.01$ & $0.06 \pm 0.02$ & $P>0.05$ \\
\hline $\begin{array}{l}\text { Oleic acid (C18: } 1 \mathrm{n}-9) \\
\text { to Stearic acid } \\
\text { (C18:0) ratio }\end{array}$ & $2.40 \pm 1.03$ & $2.24 \pm 0.54$ & $2.38 \pm 0.35$ & $1.92 \pm 0.60$ & $\begin{array}{l}\mathrm{G} 4 \text { versus } \mathrm{G} 3 \\
(P<0.05) \\
\mathrm{G} 4 \text { versus } \mathrm{G} 2 \\
(P<0.05) \\
\mathrm{G} 4 \text { versus } \mathrm{G} 1 \\
(P<0.05)\end{array}$ \\
\hline $\begin{array}{l}\text { Linoleic acid (C18: } \\
\text { 2n-6) to Oleic acid } \\
(\mathrm{C} 18: 1 n-9) \text { ratio }\end{array}$ & 0 & 0 & $0.13 \pm 0.04$ & $0.32 \pm 0.14$ & $\begin{array}{l}\text { G3 versus G4 } \\
(P<0.05)\end{array}$ \\
\hline $\begin{array}{l}\text { Oleic acid (C18: 1n-9) } \\
\text { to Palmitic acid } \\
\text { (C16:0) ratio }\end{array}$ & $0.72 \pm 0.14$ & $0.70 \pm 0.18$ & $0.68 \pm 0.07$ & $0.83 \pm 0.29$ & $\begin{array}{l}\mathrm{G} 4 \text { versus } \mathrm{G} 3 \\
(P<0.05) \\
\mathrm{G} 4 \text { versus } \mathrm{G} 2 \\
(P<0.05) \\
\mathrm{G} 4 \text { versus } \mathrm{G} 1 \\
(P<0.05)\end{array}$ \\
\hline
\end{tabular}

G1: Control, G2: HFD, G3: HFD + Sim. 2 mg/kg/day, G4: HFD + Sim. 20 mg/kg/day. HFD: High fat diet and Sim.: Simvastatin 


\section{Discussion}

In this study, we investigated changes in Acetyl-CoA carboxylase 1 and fatty acid synthetase enzymes mRNA expression levels and fatty acid proportion and concentration in rats treated with HFD and different dosage of simvastatin. Fatty acid synthesis in mammalian tissues needs the acetyl-CoA carboxylase and fatty acid synthetase enzymes. Some studies have shown that fatty acid synthesis can regulate by some factors such as a variety of nutrition and hormones. These factors may have an effect on activities of acetyl CoA carboxylase and fatty acid synthetase ${ }^{33}$. It has been revealed that the acetyl-CoA carboxylase and fatty acid synthetase activities may be changed in short and long term, respectively ${ }^{34}$. Previous studies indicated that meal-trained rats obtain metabolic equilibrium within 1.5-2 hrs. after the meal has been begun and gene expression is sustained for an additional 3 hrs. ${ }^{35-38}$.

Some other studies revealed that elevation of hepatic malonyl-CoA concentrations occur 10 -fold during the first $1 \mathrm{hr}$. of meal consumption. The high level of hepatic malonyl-CoA concentrations production is maintained for an additional $3 \mathrm{hrs} .{ }^{35-37}$. It has been reported that hepatic FAS gene expression increases 20 -fold within $2 \mathrm{hrs}$. after the meal starts. The higher rate of gene transcription is maintained for at least $2 \mathrm{~h}$ after finalizing of the $3 \mathrm{~h}$ meal ${ }^{38}$. In our study, the mRNA expression of Acetyl-CoA carboxylase 1 and fatty acid synthetase enzymes did not show any significant differences after treatment with HFD and different dosage of simvastatin after 10 weeks. Our results were not in agreement with the above mentioned findings ${ }^{6 \& 35 \& 39}$.

Acetyl-CoA carboxylases (ACCs) enzymes are involved in the synthesis and oxidation of fatty acids and have been targeted for the treatment of metabolic diseases such as type 2 diabetes and dyslipidaemia ${ }^{3}$.The ACCs inhibition might be expected to decrease fatty acid synthesis and increasing fatty acid oxidation. Studies indicated that high fat diet stimulates ACC1 expression in the liver ${ }^{6}$ and another, study indicated that lovastatin increases fatty acid biosynthesis in cultured hepatocytes by activating $\mathrm{ACC}^{39}$ which are in agreement with our study, but the increase of enzyme expression was not significant (table 5). Some studies have shown that malonyl CoA not only controls fatty acid metabolism but also has an important signaling function through its allosteric inhibition of carnitine palmitoyltransferase 1. This enzyme has an important role on flux of control over mitochondrial $\beta$-oxidation ${ }^{40}$.

Some studies have shown that there is generally a close correlation between levels of FAS mRNA and the activities of the enzyme in liver and adipose tissue ${ }^{41}$. The other studies have demonstrated that the relative mRNA level and the rate of synthesis of FAS increase in mouse pre -adipocytes ${ }^{42}$ and upon feeding in the avian liver ${ }^{41}$ which was in agreement with our study that the FAS mRNA expression was increased when all groups compared to the G1, but it was not significant $(P>0.05)$. Study of Back et $a l .^{43}$ have indicated that feeding and fasting regulated FAS synthesis at the level of transcription. Slight increase in FAS mRNA may be the reason of a slight increase in some fatty acid consumptions. A study have shown that source of fatty acid decreases the induction of liver fatty acid synthetase activity by a combination of a decreased rate of synthesis of the enzyme and an increased rate of degradation. This may be a specific effect of the polyunsaturated fatty acid in the diet ${ }^{34}$. It seems that there may be a sensitive controlling mechanism. In the present study, we showed the effect of HFD on ACC1 mRNA expression. Malonyl-CoA produces by ACC, which is the substrate for fatty acyl CoA synthase (FAS). FAS is an enzyme synthesis fatty acids ${ }^{3}$. A study in cultured hepatocytes showed that lovastatin increased fatty acid biosynthesis by activating $\mathrm{ACC}^{44}$. Our study indicated that ACC1 mRNA expression is decreased when G4 group is treated by HFD and $20 \mathrm{mg}$ simvastatin $(P>0.05)$. This means that the enzyme level decrease to produce fatty acid in this group. We found that simvastatin is not significantly affected transcript levels of ACC1 and FAS $(P>0.05)$ that malonyl CoA regulate 
fatty acid metabolism. It has also a signaling function by way of carnitine palmitoyl transferase 1 inhibition. This enzyme can regulate flux control over mitochondrial $\beta$ oxidation $^{40}$.

It seems that there is a link between the decrease of ACC expression in rats treated with HFD and $20 \mathrm{mg}$ simvastatin and regulation of fatty acid metabolism. We evaluated the effects of high fat diet and different dosage of simvastatin on serum fatty acids in rats. The main finding of this study is the increase of linoleic acid and total fatty acid when the rats were treated with HFD and $20 \mathrm{mg}$ simvastatin. This maybe means that simvastatin increased the formation of polyunsaturated fatty acids (linoleic acid). The findings of the present study also show that $20 \mathrm{mg}$ simvastatin is associated with a significant reduction in the palmitic acid (saturated fatty acid) in G4 group, but it has no effect on stearic acid (saturated fatty acid). It means that $20 \mathrm{mg}$ simvastatin reduced palmitic acid. Therefore, the decrease in the palmitic acid level after $20 \mathrm{mg}$ simvastatin therapy may have an important role to prevent risk of cardiovascular disease. Our study also showed that there are no significant differences in the oleic acid and Palmitoleic acid levels after 2 and $20 \mathrm{mg}$ simvastatin therapy. According to our findings, use of different dosages of simvastatin may show different effect on lipid metabolism in our body (in different conditions). Some studies have indicated that acetyl coenzyme A carboxylase and fatty acid synthetase could be regulated by statin at the genomic level ${ }^{45 \& 46}$

There are limited data on the effects of statins on fatty acid level in humans. Statins appear to have effects on the metabolism and serum fatty acid composition. The exact mechanisms of statins effects are not clear and it needs more future studies. It has been shown that high fat diets without in linoleic acid stimulate lipogenesis in the liver ${ }^{47 \& 48}$. In our study, used high fat diet included some saturated and unsaturated fatty acids and different dosage of simvastatin, increased levels of FAS mRNA expression, but it was not significant (Table 5). Some studies have been indicated that fatty acid synthesis was related inversely to the dietary polyunsaturated fat concentration, but not changed by saturated $\mathrm{fat}^{49 \& 50}$

In our study, the increase of fatty acid ratio, total fatty acid and linoleic acid are shown in G4 groups. This means that simvastatin therapy may increase desaturase enzyme activity. Therefore, the increase in linoleic acid concentration and unsaturated fatty acid ratio after simvastatin therapy may have important clinical benefit to prevent the possible progression of atherogenesis and cardiovascular risk.

A study showed that cardiovascular risk mortality and myocardial revascularization risk was decreased by $42 \%$ and $37 \%$ after use of the daily dosage of 20-40 mg of simvastatin for a long time, respectively ${ }^{51}$. Some other studies have indicated that the uses of high dosages of simvastatin relate to an increased risk of new onset diabetes $^{44}$.

Numerous studies have indicated that a high saturated fat taking in caused an elevation of free fatty acid, and increased free fatty acid showed a toxic effect on the body, causing damage to the function of pancreatic beta cell, promoting cell apoptosis, and impaired glucose-stimulated insulin secretion ${ }^{52}$.

The discrepancy between our results and results of other findings may be due to differences in for example study design, diet, animal species and duration of study (10 weeks) investigated. Thus, it seems that the use of different dosage of simvastatin for a long time may decrease risk of some diseases. Simvastatin may accumulate acetyl CoA, a precursor of fatty acid synthesis. Thus, a consequence of simvastatin treatment is that it could goes to intracellular accumulation of fatty acids. However, the mechanism effect of simvastatin is still unclear.

There were some limitations in our study. We measured only limited serum fatty acid composition. The formation of some fatty acid in our study was not measured here. In other words, we could only measure the fatty acids mentioned in this study. Thus, further studies are required to assess the effect of simvastatin 
on fatty acid composition to achieve more information about the simvastatin effects on fatty acid composition.

\section{CONCLUSION}

In conclusion, the results of this study showed that treatment with simvastatin significantly increases or decreases some fatty acid ratio, serum fatty acid and total fatty acid concentrations. We also found that HFD led to no significant differences in ACC1 and FAS mRNA expression. Simvastatin increases proportion of linoleic acid to oleic acid, oleic acid to palmitic acid and oleic acid to stearic acid. Thus, statin therapy may be considered in prevention of cardiovascular and myocardial risk.

\begin{abstract}
Abbreviations
G1: Control, G2: HFD, G3: HFD+Sim. 2 $\mathrm{mg} / \mathrm{kg} /$ day, G4: HFD + Sim. $20 \mathrm{mg} / \mathrm{kg} /$ day. HFD: High fat diet; Sim.: Simvastatin; ACC1: Acetyl CoA carboxylase 1; FAS: Fatty acid synthase and Beta-actin (ACTB)
\end{abstract}

\section{Availability of data and materials}

The datasets used and/or analyzed during the current study are available from the corresponding author on reasonable request.

\section{Ethical approval and consent to participate}

The ethnic committee of Golestan University of Medical Sciences approval the study (With ethics number: IR.GOUMS.1396.41). We obtained written informed consent to use the animals in our study from the Research Deputy of Golestan University of Medical Science but the rats were provided from Institute of Pasteur, Tehran, Iran.

\section{Acknowledgement}

The authors would like to thank the Research Deputy of Golestan University of Medical Sciences for financial support. This research project was derived from MSc thesis in Clinical Biochemistry. The corresponding author wishes to thank Mr. Abbas
Nezhadebrahimi and Mr Majid Marjani for their sincere help.

\section{REFERENCES}

1. L. Tabernero, V. W. Rodwell and C.V. Stauffacher, "Crystal structure of a statin bound to a class II hydroxymethylglutarylCoA reductase", J Biol Chem, 278, 19933-19938 (2003).

2. C. Stancu and A. Sima, "Statins: mechanism of action and effects", $\boldsymbol{J}$ Cell Mol Med, 5, 378-387 (2001).

3. K. H. Kim, "Regulation of mammalian acetyl-coenzyme A carboxylase", Annu Rev Nutr, 17, 77-99 (1997).

4. S. J. Wakil, J. K. Stoops and V. C. Joshi, "Fatty acid synthesis and its regulation", Annu Rev Biochem, 52, 537-79 (1983).

5. A. Bianchi, J. L. Evans, A. J. Iverson, A. C. Nordlund, T. D. Watts and L. A. Witters, "Identification of an isozymic form of acetyl-CoA carboxylase", J Biol Chem, 265, 1502-1509 (1990).

6. R. Ren, J. Gong, Y. Zhao, X. Zhuang, Y. Ye, F. Huang, et al., "Sulfated polysaccharide from Enteromorpha prolifera suppresses SREBP-1c and ACC expression to lower serum triglycerides in high-fat diet-induced hyperlipidaemic rats", J F unct Foods, 40, $722-728$ (2018).

7. M. R. Munday, C.J. Hemingway, "The regulation of acetyl-CoA carboxylase-a potential target for the action of hypolipidemic agents", Adv Enzyme Regul, 39, 205-234 (1999).

8. M. S. Davis, J. Solbiati and J. E. Cronan, "Overproduction of acetyl-CoA carboxylase activity increases the rate of fatty acid biosynthesis in Escherichia coli", J Biol Chem, 275, 28593-28598 (2000).

9. M. Hasslacher, A. S. Ivessa, F. Paltauf and S. D. Kohlwein, "Acetyl-CoA carboxylase from yeast is an essential enzyme and is regulated by factors that control phospholipid metabolism", J Biol Chem, 268, 10946-10952 (1993). 
10. D. Mozaffarian, "Free fatty acids, cardiovascular mortality, and cardiometabolic stress", Eur Heart J, 28, 2699-2700 (2007).

11. E. H. Goh, M. Heimberg, Stimulation of hepatic cholesterol biosynthesis by oleic acid, Biochem Biophys Res Commun, 55, 382-388 (1973).

12. G. F. Lewis, K.D. Uffelman, L.W. Szeto, B. Weller and G. Steiner, "Interaction between free fatty acids and insulin in the acute control of very low density lipoprotein production in humans", J Clin Invest, 95, 158-166 (1995).

13. I. Kaneko, Y. Hazama-Shimada and A. Endo, "Inhibitory effects on lipid metabolism in cultured cells of ML-236B, a potent inhibitor of 3-hydroxy-3methylglutaryl-coenzyme-A reductase", Eur J Biochem, 87, 313-321 (1978).

14. A. W. Alberts, "Discovery, biochemistry and biology of lovastatin", Am J Cardiol, 62, 10J-15J (1988).

15. R. Fears, D.H. Richards and H. "Ferres, The effect of compactin, a potent inhibitor of 3-hydroxy-3-methylglutaryl coenzymeA reductase activity, on cholesterogenesis and serum cholesterol levels in rats and chicks", Atherosclerosis, 35, 439-449 (1980).

16. S. T. Mosley, S.S. Kalinowski, B.L. Schafer and R.D. Tanaka, "Tissueselective acute effects of inhibitors of 3hydroxy-3-methylglutaryl coenzyme A reductase on cholesterol biosynthesis in lens", J Lipid Res, 30, 1411-1420 (1989).

17. W. R. Bensch, T.S. Ingebritsen and E.R. Diller, "Lack of correlation between the rate of cholesterol biosynthesis and the activity of 3-hydroxy-3-methylgutaryl coenzyme $\mathrm{A}$ reductase in rats and in fibroblasts treated with ML-236B", Biochem Biophys Res Commun, 82, 247254 (1978).

18. W. L. Isley, W.S. Harris and J.M. Miles, "The effect of high-dose simvastatin on free fatty acid metabolism in patients with type 2 diabetes mellitus", Metabolism, 55, 758-762 (2006).
19. P. Rise, F. Pazzucconi, C. Sirtori and C. Galli, "Statins enhance arachidonic acid synthesis in hypercholesterolemic patients", Nutr Metab Cardiovasc Dis: NMCD, 11, 88-94 (2001).

20. D. Tripathy, P. Mohanty, S. Dhindsa, T. Syed, H. Ghanim, A. Aljada, et al, "Elevation of free fatty acids induces inflammation and impairs vascular reactivity in healthy subjects", Diabetes, 52, 2882-2887 (2003).

21. C. F. Semenkovich, "Regulation of fatty acid synthase (FAS)", Prog Lipid Res, 36, 43-53 (1997).

22. R. Roberts, L. Hodson, A. Dennis, M. J. Neville, S.M. Humphreys, K.E. Harnden, et al, "Markers of de novo lipogenesis in adipose tissue: associations with small adipocytes and insulin sensitivity in humans", Diabetologia, 52, 882-890 (2009).

23. D. Schleinitz, N. Kloting, A. Korner, J. Berndt, M. Reichenbacher, A. Tonjes, et $a l$, "Effect of genetic variation in the human fatty acid synthase gene (FASN) on obesity and fat depot-specific mRNA expression", Obesity (Silver Spring), 18, 1218-1225 (2010).

24. J. M. Fernandez-Real, J. A. Menendez, J. M. Moreno-Navarrete, M. Blüher, A. Vazquez-Martin, M. J. Vázquez, et al, "Extracellular fatty acid synthase: a possible surrogate biomarker of insulin resistance", Diabetes, 59, 1506-1511 (2010).

25. A. Jula, J. Marniemi, R. Huupponen, A. Virtanen,M. Rastas and T. Rönnemaa, "Effects of diet and simvastatin on serum lipids, insulin, and antioxidants in hypercholesterolemic men: a randomized controlled trial", Jama, 287, 598-605 (2002).

26. M. L. Williams, G. K. Menon and K.P. Hanley, "HMG-CoA reductase inhibitors perturb fatty acid metabolism and induce peroxisomes in keratinocytes", $\boldsymbol{J}$ Lipid Res, 33, 193-208 (1992).

27. P. Rise, C. Colombo and C. Galli, "Effects of simvastatin on the metabolism of 
polyunsaturated fatty acids and on glycerolipid, cholesterol, and de novo lipid synthesis in THP-1 cells", $\boldsymbol{J}$ Lipid Res, 38, 1299-1307 (1997).

28. A. Jula, J. Marniemi, T. Rönnemaa and R. Aonen, "Effects of diet and simvastatin on fatty acid composition in hypercholesterolemic men: a randomized controlled trial", Arterioscler Thromb Vasc Biol, 25, 1952-1959 (2005).

29. P. Rise, F. Pazzucconi, C.R. Sirtori and C. Galli, "Statins enhance arachidonic acid synthesis in hypercholesterolemic patients", Nutr Metab Cardiovasc Dis, 11, 88-94 (2001).

30. K. Srinivasan, P.S. Patole, C.L. Kaul and P. Ramarao, "Reversal of glucose intolerance by by pioglitazone in high fat diet-fed rats", Methods Find Exp Clin Pharmacol, 26, 327-333 (2004).

31. A. Pocathikorn, R.R. Taylor, I. James and C.D. Mamotte, "LDL-receptor mRNA expression in men is downregulated within an hour of an acute fat load and is influenced by genetic polymorphism", $\boldsymbol{J}$ Nutr, 137, 2062-2067 (2007).

32. D. Van Wijngaarden, "Modified rapid preparation of fatty acid esters from lipids for gas chromatographic analysis", Anal Chem, 39, 848-849 (1967).

33. R. Misir, B. Laarveld and R. Blair, "Evaluation of a rapid method for preparation of fatty acid methyl esters for analysis by gas-liquid chromatography", $\boldsymbol{J}$ Chromatogr, 331, 141-148 (1985).

34. P. K. Flick and J. Chen, P. Vagelos, "Effect of dietary linoleate on synthesis and degradation of fatty acid synthetase from rat liver", J Biol Chem, 252, 42424249 (1977).

35. D. Veloso and R.L. Veech, "Stoichiometric hydrolysis of long chain acyl-CoA and measurement of the CoA formed with an enzymatic cycling method", Anal Biochem, 62, 449-460 (1974).

36. M. D. Wilson, W.L. Blak, L.M. Salati and S.D. Clarke, "Potency of polyunsaturated and saturated fats as short-term inhibitors of hepatic lipogenesis in rats", $\boldsymbol{J}$ Nutr, 120, 544-552 (1990).

37. B. A. Clarke and S.D. Clarke, "Polymerprotomer transition of acetyl-CoA carboxylase as a regulator of lipogenesis in rat liver", Arch Biochem Biophys, 218, 92-100 (1982).

38. S. D. Clarke, M.K. Armstrong and D.B. Jump, "Nutritional control of rat liver fatty acid synthase and S14 mRNA abundance", J Nutr, 120, 218-224 (1990).

39. M. Guzman, J.P. Cortes and J. Castro, "Effects of lovastatin on hepatic fatty acid metabolism", Lipids, 28, 1087-1093 (1993).

40. D. Saggerson, "Malonyl-CoA, a key signaling molecule in mammalian cells", Annu Rev Nutr, 28, 253-272 (2008).

41. G. Shillabeer, J. Hornford, J. Forden, N. Wong and D. Lau, "Hepatic and adipose tissue lipogenic enzyme mRNA levels are suppressed by high fat diets in the rat", $\boldsymbol{J}$ lipid Res, 31, 623-631 (1990).

42. J. D. Paulauskis and H. Sul, "Cloning and expression of mouse fatty acid synthase and other specific mRNAs. Developmental and hormonal regulation in 3T3-L1 cells", J Biol Chem, 263, 70497054 (1988).

43. D. Back, M. Goldman, J. Fisch, R. Ochs and A. Goodridge, "The fatty acid synthase gene in avian liver. Two mRNAs are expressed and regulated in parallel by feeding, primarily at the level of transcription", J Biol Chem, 261, 41904197 (1986).

44. M. Guzmán, J. P. Cortés and J. Castro, "Effects of lovastatin on hepatic fatty acid metabolism", Lipids, 28, 1087-1093 (1993).

45. T. F. Osborne, J. L. Goldstein and M.S. Brown, "5' end of HMG CoA reductase gene contains sequences responsible for cholesterol-mediated inhibition of transcription", Cell, 42, 203-212 (1985).

46. M. Nakanishi, J. L. Goldstein and M.S. Brown, "Multivalent control of 3-hydroxy3-methylglutaryl coenzyme A reductase. Mevalonate-derived product inhibits 
translation of mRNA and accelerates degradation of enzyme", J Biol Chem, 263, 8929-8237 (1988).

47. G. R. Herzberg, "The influence of dietary fatty acid composition on lipogenesis", Adv Nutr Res, 5, 221-253 (1983).

48. G. Herzberg and N. Janmohamed, "Regulation of hepatic lipogenesis by dietary maize oil or tripalmitin in the meal-fed mouse", Br J Nutr, 43, 571-579 (1980).

49. J. Triscari, J.G. Hamilton and A.C. Sullivan, "Comparative effects of saturated and unsaturated lipids on hepatic lipogenesis and cholesterogenesis in vivo in the meal-fed rat", $\boldsymbol{J}$ Nutr, 108, 815-25 (1978).
50. Randomised trial of cholesterol lowering in 4444 patients with coronary heart disease: the Scandinavian Simvastatin Survival Study (4S), Lancet, 344, 13831389 (1994).

51. N. Sattar, D. Preiss, H. M. Murray, P. Welsh, B. M. Buckley, A.J. de Craen, et al., "Statins and risk of incident diabetes: a collaborative meta-analysis of randomised statin trials", Lancet, 375, 735-742 (2010).

52. S. Shao, Y. Yang, G. Yuan, M. Zhang and $\mathrm{X}$. Yu, "Signaling molecules involved in lipid-induced pancreatic beta-cell dysfunction", DNA Cell Biol, 32(2), 4149 (2013). 

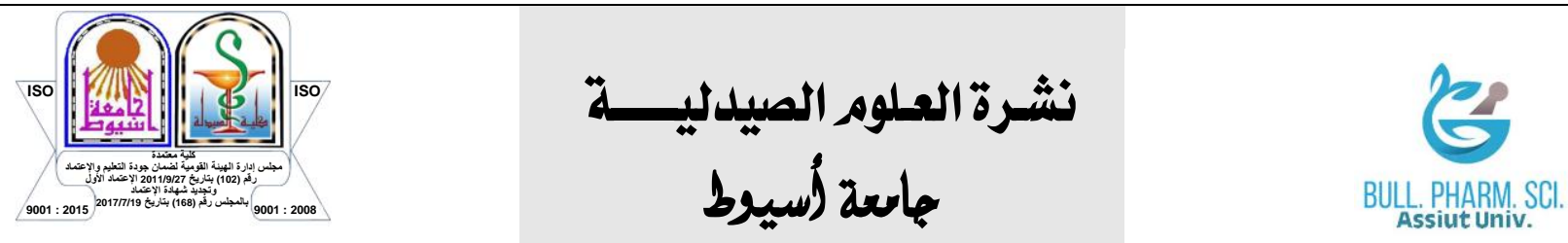

تأثير سيمفاستاتين على التعبير الجينى لكربوكسيليز الأسيتيل كو إيها وسنثاز

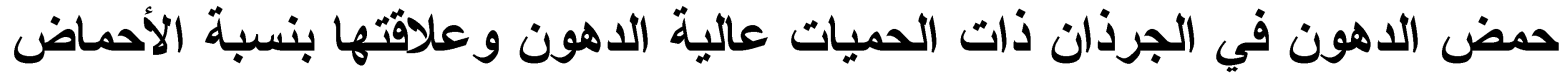

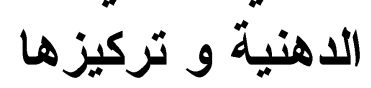

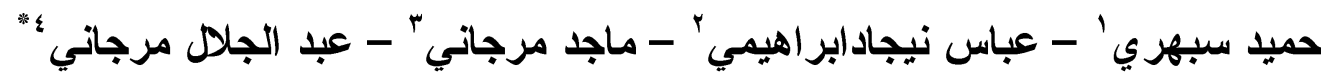

' مركز أبحاث علم الأعصاب ، قسم علم وظائف الأعضاء ، كلية الطب ، جامعة جولستان للعلوم الطبية ، جورجان ، إيران r لجنة أبحاث الطلاب ، مركز أبحاث الاضطرابات الأيضية ، قسم الكيمياء الحيوية والفيزياء الحيوية ، كلية

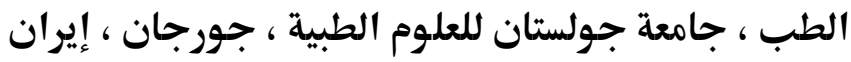

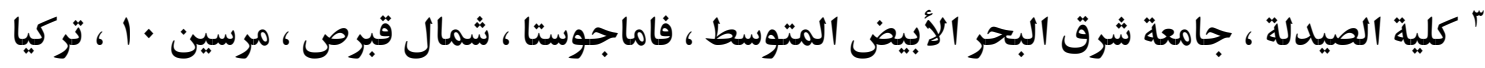

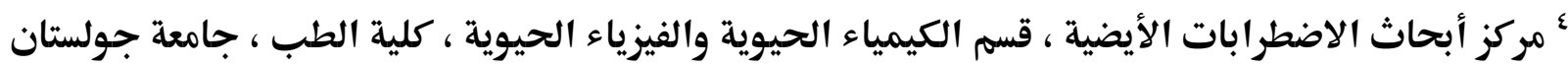
للعلوم الطبية ، جورجان ، إيران الان الانية

كان الهدف من الدراسة هو تحديد تأثير الجرعات المختلفة من سيمفاستاتين على التعبير الجيني

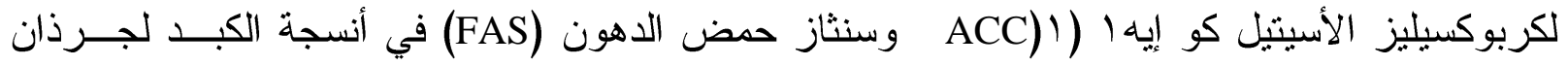

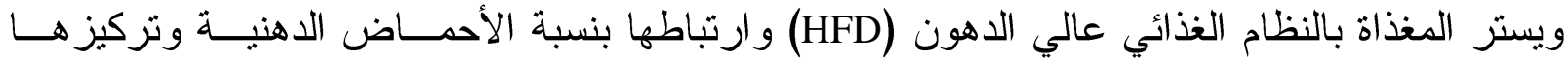

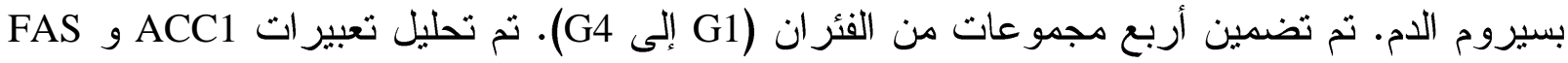

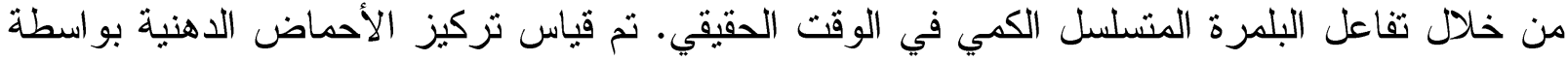

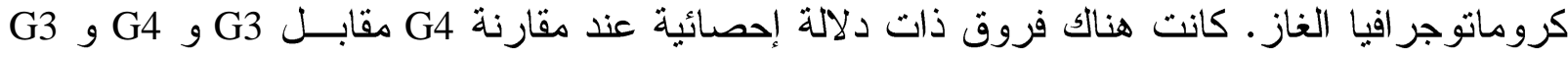

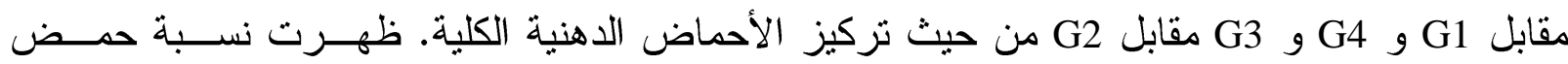

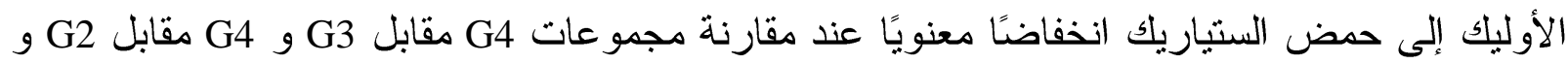

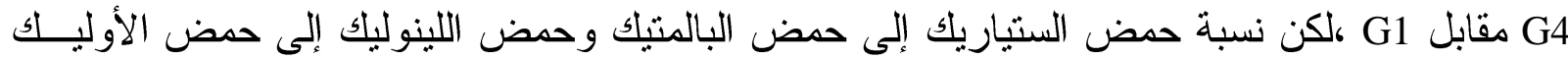

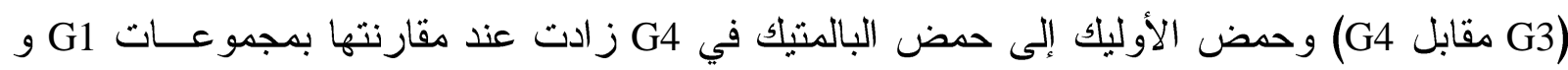

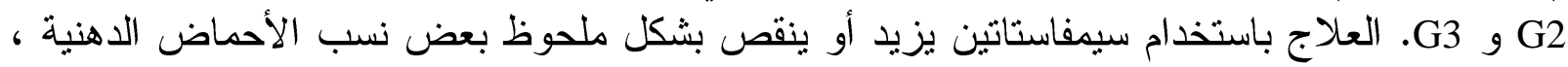

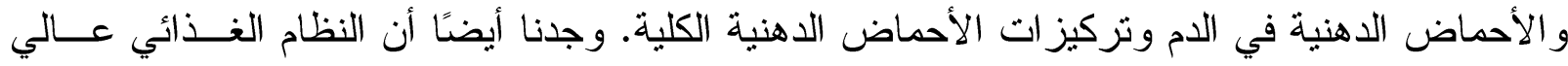

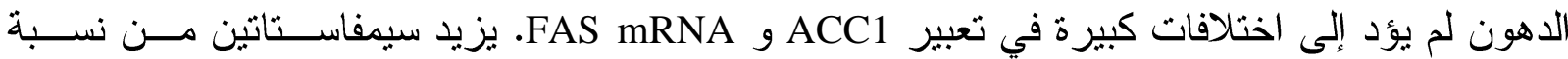

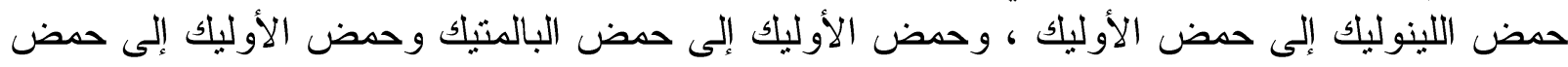

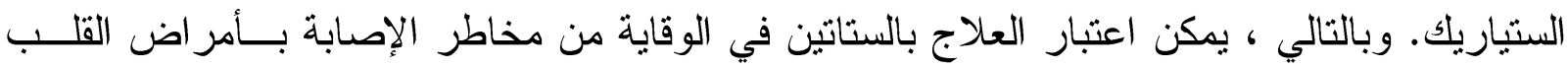
و الأو عية الدموية وعضلة القلب. 